\title{
An Overview of Micro-Lecture in College English Teaching in Mainland China
}

\author{
Min Cao ${ }^{1,2}$ \\ ${ }^{1}$ School of Foreign Language Studies, Henan Polytechnic University, Jiaozuo, China \\ ${ }^{2}$ School of Languages, University of Portsmouth, Portsmouth, UK
}

Email address:

cmada@hpu.edu.cn

To cite this article:

Min Cao. An Overview of Micro-Lecture in College English Teaching in Mainland China. International Journal of Language and Linguistics. Vol. 5, No. 2, 2017, pp. 34-38. doi: 10.11648/j.ijl1.20170502.12

Received: February 3, 2017; Accepted: February 20, 2017; Published: March 24, 2017

\begin{abstract}
With the rapid development of information technology, Micro-lecture was applied into higher education. This article attempts to study its application in College English Teaching in Mainland China by taking documentary research method through analyzing all the papers published about micro-lecture and College English teaching in CNKI (China National Knowledge Infrastructure). The data collected shows that micro-lectures were applied into College English teaching, and it is a critical point to select lecture's content. Meanwhile, teachers' role is changed with the emergence of Micro-lecture in College English teaching. Seemingly, this paper sheds light on a general study of micro-lecture in College English teaching for College English teachers and researchers and provides further improvement for College English teaching.
\end{abstract}

Keywords: Micro-Lecture, College English Teaching, Content, Teaching Mode, Teachers' Role

\section{Introduction}

Micro-lecture alternates with mini-course, micro-course, mini-lecture was proposed by David Penrose in 2008. The prototype appeared earlier in 1960 when a school of the University of Iowa in the United States put forward short term course which showed the early history of fragmenting knowledge into smaller course units. Penrose proposed the following five steps to design a microlecture: (1) List the core content of teaching; (2) Write an introduction and summary about 15 to 30 seconds; (3) Record a 1 to 3 minutes video; (4) Design after-class task; (5) Upload the video and corresponding tasks to curriculum management system [1]. Morris (2009) thought the concept of micro-lecture proposed by Penrose relies on the form of network course which provides a new approach for real classroom teaching [2] Additionally, the core content of the micro-lectures is in line with the teaching objective and students' learning experience. Later on, the concept of micro-lecture was brought into Mainland China. Hu Tiesheng (2011) proposed the concept of “微课”, the Chinese corresponding translation of micro-lecture, and pointed out that micro-lecture takes video as the main carrier, records the whole process of teaching and learning activities done by the teacher in class teaching around certain knowledge points [3]. Professor Zhang Yichun (2013) defined micro-lecture as a brief presentation of the whole process of teaching activity about certain knowledge points through meticulous informationalization instructional design to facilitate learners' autonomous learning [4]. From their explanation, we can know that micro-lecture is not a concentration of the content in the traditional classroom, but the teacher decomposes teaching content, and reconstructs them according to knowledge inner link. Knowledge points' videos are made with resources of teaching material, such as Power Point, exercises, to let students achieve personalized learning. Such characteristics of micro-lecture meet the need of College English in Mainland China.

As a required course in Chinese universities, College English has been striving for reforms. In 2007, Chinese Ministry of Education (MOE) published College English Curriculum Requirements (CECR), it states that 'All 
universities should adopt modern technology, especially computer and classroom based teaching model in their College English teaching models to supplement the teachercentered single-type teaching model. These new teaching models should build on modern information technology, particularly network technology to ensure College English learning free from time and place restrictions, which develop into those classes facilitate students' autonomous and individualized learning.' (2007, p. 18) [5] All of the universities in Mainland China have taken multimedia classroom instruction, which combines with the emergence of micro-lecture prompt the quickly increasing number of micro-lectures. Additionally, the annual foreign language micro-lecture competitions held by Higher Education Press and Foreign Language Teaching and Research Press (FLTRP) Star Teacher Contest encourage thousands of College English teachers to participate in them. Is there any difference in College English teaching like its teaching mode, content and even teachers' role? This article tends to describe the general status of micro-lecture in College English teaching in Mainland China by combing the research contents of papers published in CNKI.

\section{Micro-Lecture in College English Teaching}

\subsection{Data Collection}

The data in this paper is collected by inserting 微课大学英 语 (the corresponding Chinese words for micro-lecture, College English) to browse for the theme of all papers published in CNKI. There are 351 papers shown when the data was collected in January, 2017. In Figure. 1, it is shown that the first paper about combination of micro-lecture with College English appeared in 2013, the number of papers increased greatly year by year. In 2015 , the paper numbers about micro-lecture in College English increased 8 times of that of the year 2014. The paper number in the year 2016 is nearly doubled that of the year 2015. This Figure. 1 shows that the application of micro-lecture into College English attracted greater attention of College English teachers and researchers. The following part of this article attempts to analyse the research content of those published papers, and the discussion of present status of micro-lecture in College English teaching will be done.

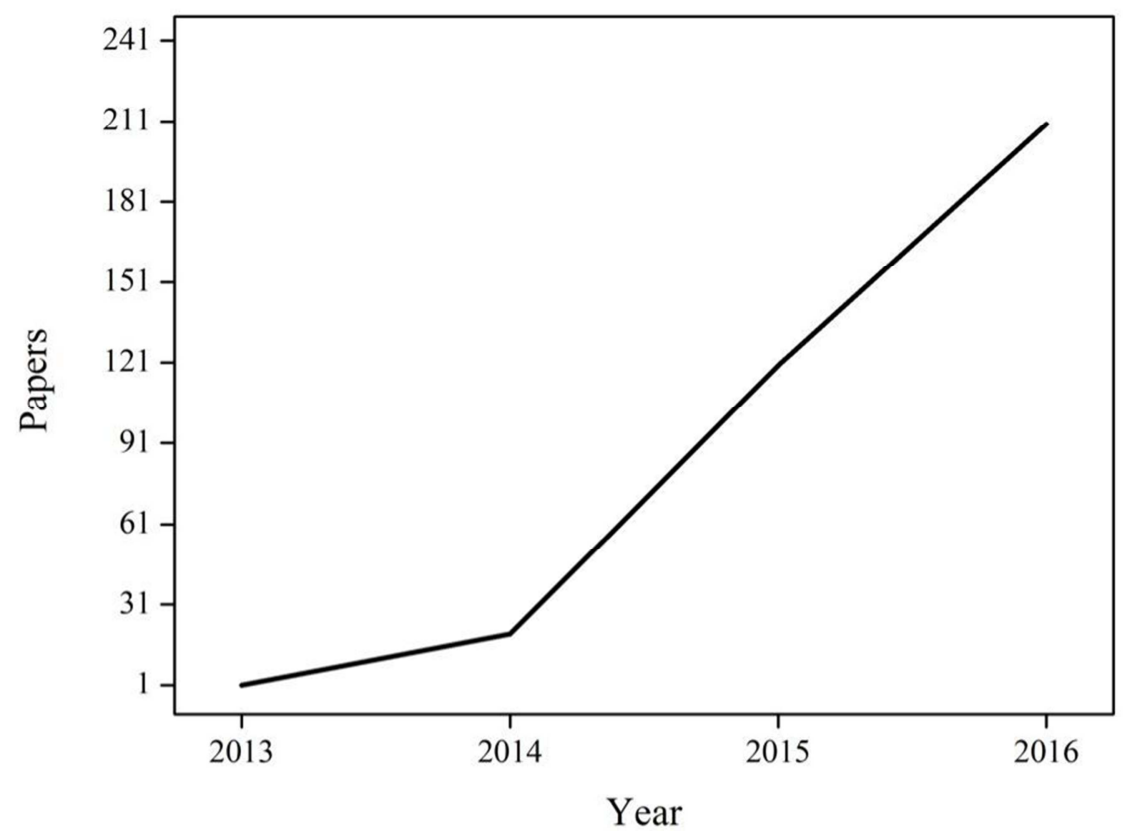

Figure 1. The number of papers in publication year.

\subsection{The Topic Issues in Researches}

While reading through and classifying all these downloaded papers about micro-lecture in College English, some of the topic issues revealed out of the papers. All the papers could be sorted out into the following categories: application of micro-lecture in College English, microlecture content selection, and teaching mode based on microlecture, and changes to College English teachers' roles.

\subsubsection{Application of Micro-Lecture Into College English}

Zhang Jie (2013) started the first step to using microlecture in College English teaching [6]. After that, a great number of researchers pay attention to micro-lecture in College English teaching, such as Ye Dan (2014) discussed deficiencies of traditional College English teaching and expected the application of micro-lecture to activate students' interest in English, modernize the teaching means and alter the single evaluation method [7]. Zhang Yunqin (2014) explored the feasibility of applying the mode of microlecture into College English classroom teaching, and tried to improve and modify the mode better by proposing four phases in class design: making micro-lecture video and develop relative material, students' autonomous learning before class, and teacher-student cooperation in class, 
summarizing and reflecting knowledge after class [8]. Most of the papers gave favourable comments on micro-lecture in College English, however, their limitations were discussed by Shao Min (2015), she stated that the less interaction in the micro-lecture give rise to students' question cannot be answered spontaneously [9]. Moreover, the specific application of micro-lecture into College English were analysed, Song Jia (2015) Studied the application of microlecture to College oral English teaching [10], Cai Yucheng (2016) and Yu Huai (2016) discussed the application to listening and speaking in College English [11][12], Zhang Chengcheng and Bai Yang (2015) and Jiang Xiaona (2015) explained the use in cultural lead-in part in College English teaching [13][14], Chen Hua (2016) analysed its application to College English reading and writing class [15], its use in translation teaching was discussed by Yao Rui (2015) [16]. From the previous researches about micro-lecture's application, it is likely that micro-lecture could be used in various aspects of teaching class.

\subsubsection{Micro-Lecture Content Selection}

It is critical to select teaching topics in College English micro-lecture, the right choice of teaching topic determines its quality or it will go back to the traditional classroom teaching. Yan Yan (2014) analysed the feature of English grammar points, reading and writing strategies, translation skills, listening and oral performance, all the points could be micro-lecture topics [17]. Zhao Yin (2015) stated that College English could be classified into skill course and content course. The former includes linguistic knowledge, micro-language skills and non-linguistic knowledge, which is more applicable to be the micro-lecture topics than the latter. In the linguistic knowledge, the phonological knowledge, grammatical knowledge, semantic knowledge and discourse structure knowledge are suitable for making micro-lectures. Secondly, the content appropriate for micro-lecture includes some of the English language skills, that is English listening, speaking, reading and writing. In English reading, microlectures can be made about fast reading (skimming and scanning), reasoning skills (inferential skills), extensive reading skills (reading span expansion) and so on. Finally, some non-linguistic knowledge including conceptual knowledge and procedural knowledge also could be chosen as the micro-lecture topics [18].

\subsubsection{Teaching Mode Based on Micro-Lecture}

With the development of micro-lecture, the corresponding teaching mode in College English class has been reformed from traditional teaching into different new teaching mode. For example, Lu Haiyan (2014) analysed the feasibility of applying micro-class based 'flippedclassroom' mode in College English teaching by studying the concepts of 'micro-class' and 'flipped-classroom', the characteristics of the College English teachers and students, the present College English teaching mode as well as the teaching environment [19]. Zhao Dandan (2016) discussed the combination of micro-lecture with traditional college teaching, this combination aims to realize the quality education and innovation education, hoping to innovate college English teaching mode and promote the reform of college English teaching [20]. Except for the previous blended learning, more innovative teaching mode have been created, for instance Peng Bingzhuan (2016) brought forth College English flipped classroom teaching mode based on micro-lecture in the mobile environment, which contributes to students' autonomous control of the learning process, increase the teacher-student and student-student interaction, and strengthen students' mental quality and comprehensive English communication competence, which can effectively solve the existing problems in college English teaching mode [21]. Mostly, researches are favourable of microlecture and its application into College English, however, different voice does exist. For example, Li Xiaoli (2016) expressed her worries about the College English microlecture quality and their limitations in application them in the teaching process [22].

\subsubsection{Change to College English Teachers' Role}

With the advance of educational informationalization, the College English teachers' role as the center of the classroom has been challenged and changed by the micro-lecture teaching mode. Gan Lingling (2015) discussed the new location of teachers' roles based on the micro-lecture context. She claimed that College English teachers should play the roles of motivator for students' learning interests and learning motivations, the explorer of micro curriculum resources, as well as the guide, facilitator, monitor and assessor of the learning effects during the process of students' self-learning, who can create the favourable conditions for the students autonomous learning and the development of their autonomous learning ability [23]. Geng $\mathrm{Na}$ (2016) stated that College English teachers should extend their role of administrators of teaching, carriers of knowledge to innovator of educational theory, planner of curriculum design, co-operator of teaching activities and reflective thinker of teaching after interviewing 50 College English teachers [24].

\subsubsection{Quantitative Research}

Among all the 351 papers collected most of them are qualitative researches, only four of them are quantitative researches published in 2016. Zhao Dandan (2016) explored the application of micro-lectures into the English teaching of Chinese medicine by comparing control group (traditional teaching group) and experimental group (micro-lecture teaching group), the results showed that students in the experimental group had significantly higher scores than those in the control group. It is concluded that the application of micro-lectures has stimulated the students' interest in learning English, met the needs of students' individualized learning and improved the English teaching quality of Chinese medicine [25]. Liu Lisha (2016) investigated the application of English reading skill micro-lectures into reading class and analysed 34 freshmen's reading feedback self-reports, the findings showed that this teaching method can improve students' English learning awareness and English language proficiency [26]. Bai 
Yang (2016) chose students of Lanzhou University of Finance and Economics and took one-term experimental teaching and monitoring. It indicated students' interests in English study and academic records have increased by multi-interactive teaching mode of micro-course online, MOOCs, social software and APP, etc [27].

\subsubsection{Other Topics}

The 351 papers are not limited to study on the previous topics, some other interesting topics are touched, such as $\mathrm{Li}$ Ye and Zhao Dongmei (2015) investigated the speech rate and MLS (mean length of sentence) of teacher talk of the prizewinning micro-courses of College English from the First contest of Foreign Language Micro-Course in Mainland China. It was found that teachers' speech rate is mechanically over slowed, which cannot benefit language acquisition. MLS is improperly short, making the teacher talk fail to function as effective comprehensible input and meanwhile increasing the risk of fossilization. Oversimplified teacher talk reduces teaching efficiency and does not help maximize comprehension [28].

\section{Implications and Limitations}

Initially, this study tries to draw a general picture of the researches of micro-lecture in College English in Mainland China. After combing and classifying the research contents and methods in the 351 papers collected in CNKI, it is likely to find out that most of the papers deal with theoretical application of micro-lectures in College English instead of using them in practical College English teaching. Statistically, the number of qualitative researches overpasses that of quantitative researches. It is possible to apply microlectures in practical College English teaching by taking all the micro-lectures in the national micro-lecture competitions and micro-lecture on MOOCs (Massive Open Online Courses) platforms at home and abroad. Furthermore, the practical application of micro-lecture activates the traditional classroom instruction, the teaching mode could be extended to blended learning of micro-lecture with traditional teaching or flipped classroom teaching, the teaching could be based on content instruction or problem learning (Barrows \& Tamblyn, 1980) [29]. The classroom instruction will be greatly facilitated by the application of micro-lecture.

The limitations of present study lie on the overview of micro-lecture in College English in Mainland China mainly accessed through collecting and analysing papers published. Considering the whole information could be possibly obtained through survey or questionnaire in Mainland China, this documentary research method seems to be the most effective way. The papers collected could not sufficiently prove the present status of micro-lecture in College English. The limitations of this paper give rise to promising researches, for example the status of College English teaching could be assessed through collecting questionnaire or interview online. The topics discussed in the collected papers could throw light on the future topics which need more attention or innovation.

\section{Conclusion}

This present paper aims at making a general overview of micro-lecture in College English teaching in Mainland China by summarizing the articles published on CNKI. The articles collected convey the information that researches on microlecture in College English are mainly concerning the theoretical expectation of its application in College English, the micro-lecture content selection, the teaching mode and the teachers' role. It seems that the College English teaching in Mainland China has been influenced greatly by the great popularity of micro-lecture. The author is concerned about the fact that comparatively less number of practical application of micro-lecture in College English were conducted, the tremendous work was taken in making microlecture will probably hinder most of over-loaded College English to implement micro-lecture in their teaching.

\section{Acknowledgements}

This research was supported by the China Scholarship Council; Soft Science Project of Henan Province 'Strategies for exporting cultural resources in Central Plains under the background of internet + : the establishment and research of the MSOC Talking Central Plains in English'. The 12th Fiveyear Plan of Henan Science of Education (2015-JKGHYB0063); The College Teaching Reform Project in Henan Polytechnic University (2015JG007; 2015JG086).

\section{References}

[1] Penrose, D. (2008). Micro lecture. Retrieved from http://baike.baidu.com/view/8495108.htm?fr=aladdin

[2] Morris, L. V. (2009). Little Lectures?. Innovative Higher Education, (2): 67-68.

[3] Hu, Tiesheng. (2011). Micro-lecture: The New Trend for the Development of Regional Education Information Resources. E-Education Research, (10): 61-65.

[4] Zhang, Yichun. (2013). How to Understand Micro-lecture? Four Qualities of Micro-lecture. Retrieved from http://blog.sina.com.cn/s/blog_8dfa9ca20101shyl.html.

[5] Higher Education Department of Education Ministry. (2007). College English Curriculum Requirements. Shanghai, China: Shanghai Foreign Language Education Press.

[6] Zhang, Jie. (2013). Micro Lecture: A Challenge and Chance of College English Teaching. Theory Research, (33): 266-267.

[7] Ye, Dan. (2014). Research on the Application of Micro-lecture in College English Teaching. Journal of Fujian Radio \& TV University, (5): 38-40.

[8] Zhang, Yunqin. (2014). Practice and Research on Microlecture of College English Teaching. Journal of Shaoguan University:Social Science, (3): 189-192. 
[9] Shao, Min. (2015). Analysis on the Application and Limitations of Micro-lecture in College English Teaching. Overseas English, (21): 81-82.

[10] Song, Jia. (2015). A Study of the Application of "Microlecture" to College Oral English Teaching: Taking Anchored Instruction as an Example. The Science Education Article Collects, (326): 170-171.

[11] Cai, Yucheng. (2016). Study on the Application of Microlecture in College English Listening and Speaking Training. English Square, (10): 98-99.

[12] Yu, Huai. (2016). On the Application of Mini-courses to College English Teaching of Listening and Speaking. Journal of Jilin Engineering Normal University, (5): 22-24.

[13] Zhang, Chengcheng \& Bai, Yang. (2015). A Tentative Research on the Lead-in Model of Chinese Culture teaching Based on Micro-lecture in College English. Dang Dai Jiao Yan Lun Cong, (2): 100.

[14] Jiang, Xiaonan. (2015). On the Application of Micro-lecture in the Cultural Lead-in in College English. Journal of Taiyuan Urban Vocational College, (10): 71-73. DOI: 10.16227/j.cnki.tycs.2015.0891.

[15] Chen, Hua. (2016). On the Application of 'Flipping Classroom' and Micro-lecture in College English Reaching and Writing Class. Journal of Higher Education, (12): 119120 .

[16] Yao, Rui. (2015). Research on the Feasibility of Embedding Micro-lecture in College English Translation Teaching. English on Campus, (2): 36-37.

[17] Yan, Yan. (2014). Research on Teaching Strategies of College English Micro-lecture. Journal of Green Science and Technology, (12): 288-289.

[18] Zhao, Yin. (2015). On the Scope of Micro-lecture Content in College English. English Square Academic Research, (1): 113-114. DOI: 10.16723/j.cnki.yygc.2015.01.057.

[19] Lu, Haiyan. (2014). Feasibility Analysis on the Application of Micro-class Based 'Flipped Classroom' Mode in College English Teaching. Computer-assisted Foreign Language Education, (158): 33-36.
[20] Zhao, Dandan. (2016). Teaching Model of the Deep Combination of Micro-lecture with Traditional College Teaching under the View of 'Internet +'. Journal of Changchun University, (12): 115-117.

[21] Peng, Bingzhuan. (2016). College English Flipped Classroom Teaching Mode Based on Micro Class in the Mobile Environment. Journal of Heilongjiang College of Education, (5): 127-129. DOI: 10.3969/j.issn.10017836.2016.05.048.

[22] Li, Xiaoli. (2016). Micro-lecture, FCM\&MOOCs: Will They Be Pioneers of College English Teaching Reform?. Journal of Shijiazhuang University of Economics, (5): 132-136. DOI: 10.13937/j. cnki.sjzjjxyxb.2016. 05.025.

[23] Gan, Lingling. (2015). On the New Roles of College English Teachers Based on Micro Class Context. Journal of Hunan Industry Polytechnic, (6): 68-70.

[24] Geng, Na. (2016). The Changing Roles of College English Teachers under the Circumstances of Micro Lesson Teaching Mode. Overseas English, (2): 28-29.

[25] Zhao, Dandan. (2016). The Application of Micro-lecture in English Teaching of Chinese Medicine. Journal of Changchun University of Chinese Medicine, (4): 853-54. DOI: 10.13463/j.cnki.cczyy.2016. 04.071.

[26] Liu, Lisha. (2016). The Qualitative Research of Embedding Reading Skills Micro-lecture in College English Classroom Teaching. Journal of Higher Education, (10): 70-72.

[27] Bai, Yang. (2016). An Empirical Study on the MultiInteractive Teaching Mode of University English in the Digital Environment - Taking Lanzhou University of Finance and Economics as an Example. Journal of Heihe Univeristy, (5): 149-151. DOI: 10.3969/j.issn.16749499.2016.05.067.

[28] Li, Ye \& Zhao, Dongmei. (2015). Teacher Talk and Its Effects in the Micro-course of College English: Based on the Investigation of Samples from the First Contest of Foreign Language Micro-Course in China. Computer-assisted Foreign Language Education, (165): 15-20.

[29] Barrows, H. \& Tamblyn, R. (1980). Problem-Based Learning: An Approach to Medical Education. New York: Springer, 67. 